\title{
Case for diagnosis
}

\author{
Caso para diagnóstico
}

\author{
Iolanda Conde Fernandes ${ }^{1}$ \\ Rosário Alves ${ }^{3}$
}

\section{CASE REPORT}

A 63-year-old Caucasian man presented with a two-month history of an intensely pruritic, symmetric and polymorphous skin eruption. His past medical history was unremarkable.

On examination, we observed multiple papules, vesicles, pustules and crusted excoriations on an erythematous base, especially over the buttocks, legs and arms (Figure 1). The oral and genital mucosas were spared. Nikolsky's sign was negative.

Tzanck smear showed abundant eosinophils with absence of acantholytic cells. Histopathological examination revealed eosinophilic spongiosis and intraepidermal vesicles filled with eosinophils and neutrophils (Figure 2). Direct immunofluorescence microscopy showed intercellular deposits of IgG (Figure 3). High titers of circulating anti-desmoglein 1 autoantibodies were demonstrated by immunoblot study. The remaining workup, which included blood tests, imagiologic studies and gastrointestinal endoscopy, was normal.

The patient was treated with $100 \mathrm{mg} /$ day dapso-

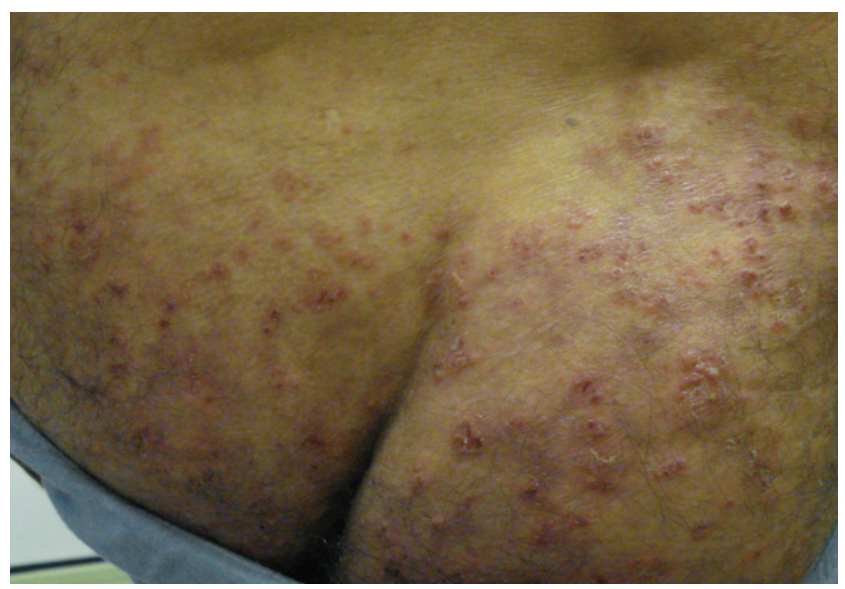

Figure 1: Clinical features showing multiple papules, vesicles, pustules and crusted excoriations on an erythematous base over the buttocks

\author{
Madalena Sanches ${ }^{2}$ \\ Manuela Selores ${ }^{4}$
}

ne and showed an excellent response. After a year, he was free of the disease on a maintenance dose of 50 mg dapsone daily.

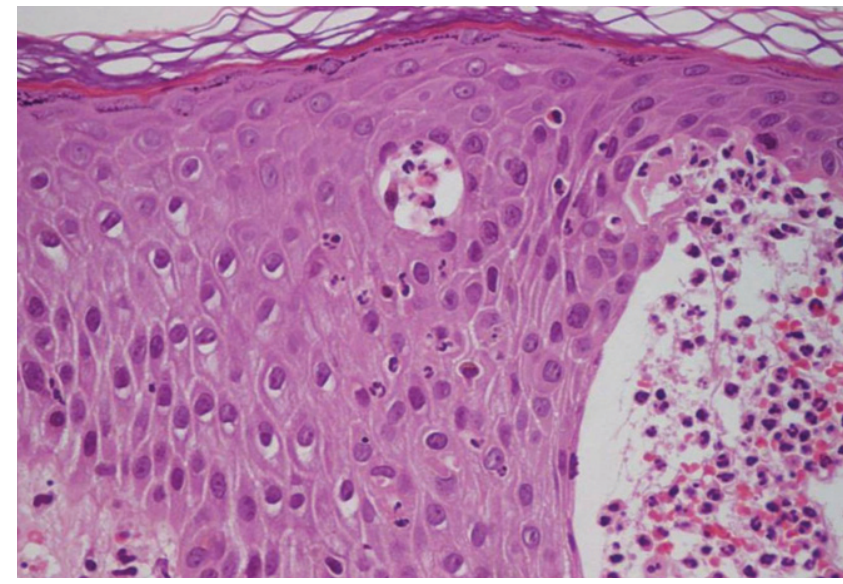

FIGURE 2: Histopathological examination revealing eosinophilic spongiosis and intraepidermal vesicles filled with eosinophils and neutrophils (Hematoxylin and Eosin staining 40x)

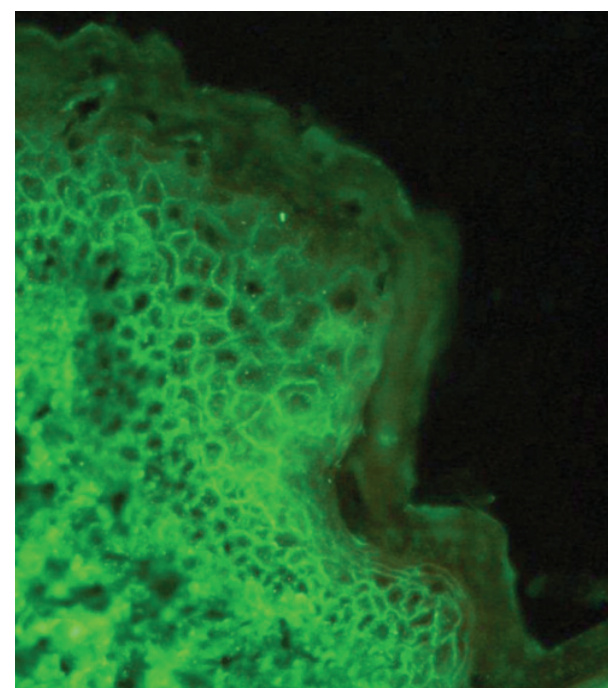

Figure 3: Direct immunofluorescence performed on perilesional skin revealing IgG deposits at the keratinocyte cell surface

Received on 14.06.2011

Approved by the Advisory Board and accepted for publication on 02.01.2012.

* Work conducted at Centro Hospitalar do Porto, EPE - Hospital Geral de Santo António - Porto, Portugal. Conflict of interest: None

Financial funding: None

Resident in Dermatology - Service of Dermatology, Centro Hospitalar do Porto (Porto Hospital Center), EPE - Hospital de Santo António (Santo António Hospital) - Porto, Portugal.

Head of the Service of Dermatology - Centro Hospitalar do Porto, EPE - Hospital de Santo António - Porto, Portugal.

Physician Assistant, Department of Dermatology - Service of Dermatology, Centro Hospitalar do Porto, EPE - Hospital de Santo António - Porto, Portugal.

Director of the Department of Dermatology, Professor of Dermatology (School of Biomedicine) - Head of the Department - Service of Dermatology, Centro Hospitalar do Porto, EPE - Hospital de Santo António - Porto, Portugal. 


\section{DISCUSSION}

Pemphigus herpetiformis $(\mathrm{PH})$ was diagnosed based on clinical, histopathological and immunological findings.

PH was first introduced by Jablonska et al. in 1975. ${ }^{1}$ It is considered a rare variant of pemphigus which combines the clinical features of dermatitis herpetiformis with the immunological findings of pemphigus. Due to its rarity and atypical presentation, $\mathrm{PH}$ is frequently misdiagnosed as dermatitis herpetiformis, pemphigus foliaceus, bullous pemphigoid and several other autoimmune bullous conditions.

Clinically, patients present with severe intractable pruritus with cutaneous lesions arranged in a herpetiform pattern, resembling the clinical picture of dermatitis herpetiformis. Histological findings vary according to the evolution of skin lesions, and typical findings of pemphigus emerge only later in the disease process. ${ }^{2}$ Therefore, several biopsies may be needed to establish a correct diagnosis. In the early stages, biopsy specimens show eosinophilic spongiosis with or without acantholytic cells and intraepidermal vesicles and bullae filled with neutrophils and eosinophils. This is an important but non-diagnostic histological reaction and it may be the initial pattern of a pre-acantholytic inflammatory stage. The finding of eosinophilic spongiosis should prompt a recommendation for other diagnostic studies. Because the clinical presentation of the disease and the histological findings are often atypical, the most consistent test for diagnosis of $\mathrm{PH}$ is immunofluorescence. ${ }^{3}$ Direct immunofluorescence (DIF) performed on perilesio- nal skin revealed intraepithelial intercellular IgG deposits, which is the typical finding. ${ }^{3}$ Most $\mathrm{PH}$ autoantibodies target desmoglein (Dsg) 1, with exceptional cases manifesting autoantibodies against Dsg 3, implicating the predominant autoimmunity similar to pemphigus foliaceus rather than pemphigus vulgaris. ${ }^{4}$ Several cases of $\mathrm{PH}$ without anti-Dsg 1-3 autoantibodies were reported. ${ }^{4}$ More recently, it has been found that many patients with $\mathrm{PH}$ also show autoantibodies against desmocollin. ${ }^{5}$

Several papers have reported clinical cases of HP associated with some neoplasms, HIV infection and medication. ${ }^{6,78}$ Diagnostic investigations in our patient showed no evidence of associated systemic disease, and he was not taking any drugs.

In general, the disease shows a benign course, with a good response to treatment. Our patient had been initially treated with prednisolone without any benefit. Therefore, he was started on dapsone with total response. Dapsone is considered the best drug for the treatment of $\mathrm{PH}$ with doses ranging from 100 to $300 \mathrm{mg}$ daily. ${ }^{2}$ It may be given as monotherapy or in association with corticosteroids and immunosuppressant drugs. It is known that superficial forms of pemphigus, those with low or negative antibody titers and histological features of eosinophilic spongiosis, respond well to dapsone. ${ }^{9}$ However, some cases of PF and PV in patients with PH have been reported. ${ }^{2,9}$ In these cases, systemic corticosteroids in combination with immunosuppressants may be required.

\footnotetext{
Abstract: We report a clinical case of a rare variant of pemphigus - pemphigus herpetiformis - which combines the clinical features of dermatitis herpetiformis with the immunological findings of pemphigus. Due to its atypical presentation, it is frequently misdiagnosed as dermatitis herpetiformis. It is basically characterized by the herpetiform pattern of skin lesions, severe pruritus and by the presence of eosinophilic spongiosis confirmed on histopathology. We call attention to the excellent response to dapsone.

Keywords: Biopsy; Dapsone; Fluorescent antibody technique; Pemphigus

Resumo: Descrevemos um caso clínico de uma variante rara de pênfigo - pênfigo herpetiforme - que combina os aspectos clínicos da dermatite herpetiforme com os achados imunológicos do pênfigo. Devido à sua apresentação atípica, é frequentemente diagnosticado equivocamente como dermatite herpetiforme. Caracteriza-se essencialmente pelo padrão herpetiforme das lesões cutâneas, prurido intenso e presença de espongiose eosinofílica no exame histopatológico. Enfatizamos a excelente resposta terapêutica à dapsona.

Palavras-chave: Biópsia; Dapsona; Imunofluorescência; Pênfigo
} 


\section{REFERENCES}

1. Jablonska S, Chorzelski TP, Beutner EH, Chorzelska J. Herpetiform pemphigus, a variable pattern of pemphigus. Int J Dermatol. 1975;14:353-9.

2. Robinson ND, Hashimoto T, Amagai M, Chan LS. The new pemphigus variants. J Am Acad Dermatol. 1999;40:649-71.

3. Aoki V, Sousa JX Jr, Fukumori LM, Périgo AM, Freitas EL, Oliveira ZN. Imunofluorescência direta e indireta. An Bras Dermatol. 2010;85:490-500.

4. Miura T, Kawakami Y, Oyama N, Ohtsuka M, Suzuki Y, Ohyama B, et al. A case of pemphigus herpetiformis with absence of antibodies to desmogleins 1 and 3. J Eur Dermatol Venereol. 2010;24:101-3

5. Tateishi C, Tsuruta D, Nakanishi T, Uehara S, Kobayashi H, Ishii M et al. Antidesmocollin-1 antibody-positive, antidesmoglein antibody-negative pemphigus herpetiformis. J Am Acad Dermatol. 2010;63:e8-10.

6. Prado R, Brice SL, Fukuda S, Hashimoto T, Fujita M. Paraneoplastic pemphigus herpetiformis with IgG antibodies to desmoglein 3 and without mucosal lesions. Arch Dermatol. 2011;147:67-71.

7. Bull RH, Fallowfield ME, Marsden RA. Autoimmune blistering diseases associated with HIV infection. Clin Exp Dermatol. 1994;19:47-50.

8. Verdier-Sevrain S, Joly P, Thomine E, Belanyl PH, Gilbert D, Tron F, et al. Thiopronine-induced herpetiform pemphigus: report of a case studied by immunoelectron microscopy and immunoblot analysis. Br J Dermatol. 1994;130:238-40.

9. Dias M, dos Santos AP, Sousa J, Maya M. Herpetiform pemphigus. J Eur Acad Dermatol Venereol. 1999;12:82-5.

\author{
MAILING ADDRESS: \\ Iolanda Conde Fernandes \\ Edifício das consultas Externas, Ex-CICAP \\ Rua D. Manuel II, s/n. Porto. Portugal - 4100 \\ E-mail: iolanda.c.fernandes@iol.pt
}

How to cite this article: Fernandes IC, Sanches M, Alves R, Selores M. Case for diagnosis. Bullous eruption with herpetiform pattern. An Bras Dermatol. 2012;87(6):933-935. 